\title{
Na Escuta do Eu-feminino, na Seara das Artes da Cena: a dramaturgia da ora- lidade como caminho de criação
}

\section{In Listening to the I-female, in the Ground of the Arts of the Scene: the drama- turgy of orality as a path of creation}

\author{
João Vítor Ferreira Nunes ${ }^{1}$ \\ Universidade do Estado de Santa Catarina - UDESC, Florianópolis/ SC, Brasil \\ E-mail: joaovitormulatto@gmail.com
}

\section{Resumo}

Neste artigo, lanço mão de uma empreitada teórico-prática na qual tive meu corpo e o lado feminino de minha personalidade, ânima (JUNG, 2000), como forças motrizes de pesquisas que acontecem na seara das artes da cena. Para a estruturação deste material, foi preciso não somente acampar em minha dimensão interior, mas também realizar uma jornada de Pesquisa de Escuta (NUNES, 2020b), procedimento metodológico este que ocorre em campo e investiga a individuação a fim de coletar narrativas outrora alocadas no próprio íntimo, para que os conteúdos sirvam de repertório para a criação de processos artísticos. Essa jornada me fez serpentear em meus campos de memória e erguer, assim, um tripé de interlocução entre psicologia analítica junguiana, práticas artísticas e narrativas autobiográficas, cujo objetivo é estabelecer encontros comigo mesma.
In this article, I use a theoretical-practical trajectory, where I had my body and the feminine side of my personality, anima (Jung, 2000), as the driving forces of research that take place in the field of the performing arts. For the structuring of this material, it was necessary not only to camp in my inner dimension, but to carry out the Listening Research journey (NUNES, $2020 \mathrm{~b}$ ), this being an individuation process that aims to uncover narratives that were once allocated in the personal/collective intimacy, so that these contents serve as a repertoire for the creation of theoretical and practical processes. Such a journey made me meander in my fields of memory, thus erecting a tripod for interlocution between jungian analytical psychology, performing practices and autobiographical narratives, whose goal is to establish meetings with myself.

\section{Palavras-chave}

Dança Pessoal. Dramaturgia da Oralidade. Energia Ânima. Feminino-masculino. Pesquisa de Escuta.
Keywords

Personal Dance. Dramaturgy of Orality. Anima Energy. Female in male. Listening research.

\footnotetext{
1 João Vítor Mulato é artista-docente interdisciplinar, licenciada em Pedagogia pela Faculdade Maurício de Nassau (UNINASSAU), Teatro e Dança pela Universidade Federal do Rio Grande do Norte (UFRN). Pós-graduada em Consciência Corporal, Saúde e Qualidade de Vida (UFRN) e Ensino de Teatro (IFRN). Mestra pelo Programa de Pós-graduação em Artes Cênicas da Universidade Federal do Rio Grande do Norte (PPGArC/UFRN). Doutoranda no Programa de Pós-graduação em Artes Cênicas da Universidade do Estado de Santa Catarina (PPGAC/UDESC). Currículo Lattes: http://lattes.cnpq.br/3721151240251862. Orcid iD: https://orcid.org/0000-0003-3066-6623.
} 


\section{Introdução - A gênese da pesquisa e sua base teórica}

Não se pode negar que existem inúmeras possibilidades de ser feminino no mundo e que não há um conjunto específico de caminhos ou feituras que nos levem a eles (BUTLER, 2019), justamente porque sua natureza selvagem, instintiva e peculiar, pertencente a todos os indivíduos é única em cada corpo e, ao mesmo tempo variável e, vem resistindo há séculos, ocupando todas as camadas da sociedade. Não se pode negar também que alguns corpos femininos são vistos como dissidentes ou abjetos e parte deles são negligenciados na sociedade. Que corpos são esses, onde eles estão, como os reconhecemos e, mais que isso, o que eles podem são questões que vieram à tona conforme eu me dedicava aos estudos acadêmicos. Esse conjunto de perguntas me levaram a este mote investigativo: o desvelar do lado feminino de minha personalidade, ânima (JUNG, 2000), e consequentemente meu próprio corpo via artes da cena.

Ao longo das pesquisas, compreendi que ele, meu corpo, não é um conjunto de partes, mas uma totalidade que agrega saberes e que pode ser visto como um corpo-bandeira que foi se tornando uma força motriz capaz de batalhar frente a situações nefastas. Assim, ele afugentou inúmeros outros corpos por meio de atos performáticos pedagógicos e políticos, com o intuito de conscientizar todos, sejam não artistas ou artistas da cena.

Neste artigo, lanço mão de uma escrita autobiográfica cujo trajeto artístico, de caráter teórico-prático vem possibilitando a autocompreensão por meio do ato de acampar na própria dimensão interior. Para isso, fez-se necessária a realização de uma jornada intitulada Pesquisa de Escuta (NUNES, 2020b). Tal procedimento metodológico confabulado por mim, artista-pesquisadora, tem o intuito de coletar minhas narrativas, via processo de individuação (JUNG, 2000), e as documentar em um Caderno de Memórias (NUNES, 2020b), para então ter material para ser estudado e "carnificado" nas salas de ensaio e, consequentemente, dar corpo e voz aos ritos de passagem na cena. Pois a meu ver não há nada mais político no campo das artes do que aprender a se ouvir e emancipar essas vozes e esses conteúdos que estão alocados no fundo de nossas memórias.

Esse processo de individuação, ao qual me referi, está estritamente relacionado à Pesquisa de Escuta (NUNES, 2020b), pois, segundo o psiquiatra suíço Carl Gustav Jung (2000), trata-se de uma jornada altamente relevante na vida de todos os sujeitos; quer dizer, ela acontece em fases e formas completamente diferentes em cada ser. Com ela, encontramos nossos próprios meios de se individualizar nas jornadas pessoais, isso conforme vamos tendo contato com outros indivíduos e com informações do mundo exterior. Essas informações então reverberam em nossos campos internos, que estão em constante expansão. Sendo assim,

[...] a personalidade de um indivíduo está destinada a individualizar-se tão fortemente quando o corpo está destinado a crescer. Mas, assim como o corpo precisa de uma alimentação adequada e de exercício para crescer de uma maneira saudável, também a personalidade necessita de experiência adequada e de educação para sua individuação sadia. (HALL, 2014, p. 71).

Nesse traçado da individuação, que venho desenvolvendo desde 2013, aprendi a ouvir e perceber a minha ânima, isto é, o lado feminino da personalidade masculina (JUNG, 2000) que influencia todos os sujeitos. Desde então, venho lapidando meu eu-feminino por meio de pesquisas acadêmicas que foram desvelando pouco a pouco quem de fato eu era e o que eu carregava.

Para apresentar o feminino no corpo masculino, Jung fez uso de uma palavra oriunda do idioma latim, ânima, que significa alma. Assim, a ânima é a essência dos sujeitos. Ela vai se aflorando nos corpos dos homens conforme o contato com mulheres de carne e osso, ou seja, mulheres que estão à nossa volta. Trata-se de um arquétipo que foi sendo rejeitado e alijado para os porões da obscuridade dos homens, por atos machistas e misóginos, de repulsa do próprio feminino. Melhor dizendo, a ânima, ao lon- 
go da história, foi sendo negada em contextos nos quais predominava o machismo, tendo essa energia ficado ainda mais reclusa no inconsciente pessoal/ coletivo dos sujeitos. Essa negação, é preciso dizer, é um mecanismo utilizado por muitos homens justamente por desconhecerem a própria ânima e terem se afinado com sua masculinidade (NUNES, 2019).

O fato é que há quase dez anos dedico meus estudos à Psicologia Analítica confabulada por Jung, vinculados aos processos teórico-práticos das artes da cena, a fim de enxergar a minha ânima e colocá-la para fora, para então fazer com que ela atue em meu corpo conforme acha coerente para si. Digo isso porque a nossa ânima possui uma personalidade própria e, conforme atua sobre nós, nos faz confundir a sua personalidade com a nossa. Assim, enxergamos nossa ânima e sua personalidade como um polo oposto a nós, apesar de elas serem altamente complementares: uma não vive sem a outra. Quer dizer, são energias dicotômicas, que se unem e se retroalimentam constantemente. O modo como ela atua foi pesquisado por Jung, que a entendeu "[...] como um arquétipo, e que influencia corriqueiramente as personalidades dos sujeitos" (NUNES; ARAúJO, OLIVEIRA, 2020c, p. 63). Além disso,

[...] cabe apontar que ninguém, jamais, conseguirá se distanciar daquilo que realmente é, nem tão pouco conseguirá negar a própria natureza instintiva, e que, num dado momento, toda essa natureza há de guiar os indivíduos para os campos apropriados que os liguem a elas/es mesmas/os [...] (NUNES; ARAÚJO; OLIVEIRA, 2020c, p. 63).

Por intermédio da atuação/do manifestar da ânima, podemos perceber que ela é apenas mais uma das diversas possibilidades de ser feminino no mundo, ainda que não seja tão valorizada, justamente por ter ficado à margem e embuçada. Em meus estudos, trago-a para os campos férteis das artes da cena, a fim de contemplá-la por outra perspectiva, ao realizar imersões corporais e artísticas, tendo como base as noções de arquétipos, mirando holo- fotes para esta constelação de conteúdos e seres.

Desenvolvimento - Serpenteando a própria interioridade, a fim de encontrar luz para si mesma: a prática

Em uma de minhas tomadas de consciência, me vi analisando meu passado, mais especificamente meu antigo lar, e concluí que ele era um ambiente altamente nocivo para as mulheres e para o feminino, muito porque era imperado por um homem misógino. Somado a isso, ao longo de minhas empreitadas acadêmicas, vim percebendo que inúmeros pesquisadores subjugam o feminino, desmerecendo-o ou mesmo o colocando em um traçado de inferioridade. Foi então que, em 2013, enquanto graduanda em Teatro na Universidade Federal do Rio Grande do Norte (UFRN), passei a me interessar pelo meu eu-feminino e, com isso, investir em estudos teórico-práticos para serpentear nessa dimensão retroalimentativa e interna chamada ânima. Todavia, eu não sabia como apresentá-la para outras pessoas, justamente por ser algo, por ora, desconhecido, que vivia embuçado, mesmo atuando em minha personalidade com frequência.

Para que ocorresse o desvelamento do meu eu-feminino, foi preciso aceitá-lo por completo, para então assumir esses seres que vêm dizendo muito sobre mim, porém, por outra perspectiva. As investidas nas práticas cênicas - Teatro, Dança e Performance - foram o álibi que utilizei ao longo dos estudos, quando ainda não conseguia falar/apresentar o meu eu-feminino. Assim, por meio da cena, a minha ânima foi se desvelando².

Na medida em que isso acontecia, fui descobrindo com a prática que minha dimensão interna era imensamente habitada por seres místicos e oníricos, mesmo sendo um território considerado por mim indevassável. Tornou-se, assim, um enorme desafio estabelecer elos com o eu-feminino, sem que eu

2 Aos interessados, favor visitar o material ÂNIMA E(M) PERFORMANCE: Cartografia poética da feminilidade. Revista Artes da Cena (2020), pois, verso também minha trajetória artística e anímica. 
viesse a confundir sua personalidade com a minha. Quis investigar, por meio de meu corpo na cena, as mulheres que habitavam minha dimensão, diferentemente de Jung, que investia no século $X X$ em imersões clínicas. Com isso, compreendi que a ânima se tratava de uma essência que faz parte de nossos corpos e que, conforme a negamos, não estamos negando apenas o eu-feminino, mas a nós mesmas de um modo geral. Ou seja, estamos na tentativa de exilar uma parte muito importante e fundamental de nós e, consequentemente de nossa história.

Por certo, sofri os efeitos de uma sociedade patriarcal que, com todas as suas formas subversivas de identidade, tenta nos distanciar de nosso eu-feminino, ofuscando-o ou, ainda, tentando impor suas crenças heteronormativas e compulsórias, crenças estas que limitam, segregam e anulam corpos e suas identidades. Percebi então que se tornou um ato de resistência política valorizar minha feminilidade dissidente.

Carl G. Jung dedicou parte de sua vida ao desvelamento da ânima. Sua intenção era afirmar que dentro do interior masculino havia, sim, uma dimensão feminina que precisava de atenção. Segundo ele, o mesmo acontecia no interior das mulheres, isto é, no interior delas, também havia a dimensão masculina, o animus, traduzido do latim como espírito. Como a ânima, o animus também busca ser valorizado e explorado de várias maneiras, sobretudo ao se manifestar por meio das projeções e identificações.

Embora a ânima e o animus carreguem em seu dorso palavras que são frequentemente vistas na esfera religiosa - alma e espírito -, Jung nada quis remeter ao cunho religioso. Sua intenção, a meu ver, sempre foi tratar de assuntos/temas que são inerentes a todos os sujeitos. $\mathrm{Na}$ verdade, ele queria, em pleno século $X X$, compreender os fenômenos que ocorriam em nosso inconsciente.

De fato, a/o ânima/animus manifestam-se em nossas vidas desde a infância, muito embora não possam ser vistos a olhos nu, mas identificados através das projeções e identificações, para além da compreensão de arquétipos. Jung nos esclarece por meio de seus escritos que eles são as imagens primordiais que se encontram presentes em nosso imaginário e que nos auxiliam nas explicações das histórias que ocorreram no passado, vividas por outras gerações. É possível que liguemos diretamente a ânima e o animus ao imaginário, e assim nos enxerguemos nas imagens ou figuras, ou mesmo vemos outras pessoas, quando se tratam de pessoas de carne e osso.

Ao passo que investigo minha ânima, via Pesquisa de Escuta/individuação na seara das artes da cena, estou em busca de compreender quem de fato sou e parte daquilo que carrego em meu íntimo imensamente povoado por imagens e figuras elementares. Busco ocupar esses espaços para desancorar de meu íntimo imagens e figuras femininas, aliando-me, assim, à minha dimensão arquetípica e subjetiva, para então (re)contar histórias orais. Concomitante a isso, como ato político, olho para mim mesma e me valorizo como ser que se alia à própria feminilidade interior e que a externaliza sem quaisquer ressentimentos, culpas ou dores, distanciando-me, assim, de imposições patriarcais de supervalorização da masculinidade tóxica e sua virilidade.

\section{Há seres femininos em meus atos ritualísticos}

Direciono-me à minha ânima a partir de imersões artísticas, tendo como plataforma - a depender da investigação - os solos do Teatro, da Dança e da Performance e desencadeio, dessa maneira, estudos acerca do corpo e de suas manifestações psíquicas. Nestas investigações artísticas, invisto no desconhecido por meio da Dramaturgia da Oralidade, sendo este um conjunto de procedimentos que visa levar os artistas/interpretes para a cena. No primeiro momento do ritual, há uma seleção de Figuras Elementares e o Jogo de Imagens, para que nessa trama se observe quais figuras guiarão os artistas/interpretes nas imersões. Tais jogos podem ser vistos como um ato revelador, consequência de uma conexão entre um eu, por vezes conhecido, e um outro eu a ser revelado no processo. Para isso, faz-se necessário mirar não apenas em si, mas nas camadas internas e nas suas imagens, 
por meio das quais somos guiadas não pela certeza ou racionalidade, mas pela inteireza desconhecida que há em nós, a ânima. De acordo com Jung,

[...] do inconsciente emanam influências determinantes, as quais, independente da tradição, conferem semelhança a cada indivíduo singular, e até identidade de experiências, bem como da forma de representá-las imaginativamente. Uma das propostas principais disto é o paralelismo quase universal dos motivos mitológicos, que denominei arquétipos, devido à sua natureza primordial. (JUNG, 2000, p. 68).

Conforme fazemos isso, tais arquétipos - ânima e animus - trarão até nós informações e conteúdos do inconsciente à medida que estivermos preparadas para lidar diretamente com eles. Quer dizer, o nosso eu-feminino/eu-masculino trabalha sob nós conforme acha coerente para si, mas sem nos tirar do eixo principal, da consciência de si.

A respeito do meu processo de criação cênica, com o pesquisador Robson Carlos Haderchpek (UFRN) aprendi a trabalhar com os elementos da natureza - água, ar, fogo e terra - e enxergá-los em mim mesma essa alquimia. Este caminho tem incitado meu lado criativo, muito porque faz eclodir imagens arquetípicas ou mesmo figuras elementares que estão presentes em nosso universo interior. Chamo de Figuras Elementares aqueles seres arquetípicos e suas imagens que estão alocados nos campos internos de nossa dimensão e que podem ser vistos como essencialmente únicos em nós. Sendo assim, na medida em que vamos investindo nas imagens, podemos então investir também nas Vivências Alquímicas, sendo este um jogo ritualístico a partir e com as imagens, onde deve-se dar estímulos como músicas, sons, áudios gravados, ou mesmo elementos cênicos, objetos e vestimentas que auxiliem na interação e nas descobertas podem ir sendo gerados ao longo das investigações. Ou seja, após algumas vivências com os elementos alquímicos, há o Jogo com os Objetos Pessoais.

Faz-se mister apontar que, tudo que for sendo vivido a partir da Dramaturgia da Oralida- de, ou seja, carnificado, deve ser registrado no Caderno de Memórias, para que tais informações não se percam. O caderno de memórias é um material indispensável que acompanhará o artista/interprete do início ao fim das imersões.

Somado a investigação, no ano de 2019 , ao fim da disciplina Seminário Temático I: Introdução ao Teatro Feminista, ofertada no Programa de Pós-Graduação em Artes Cênicas da Universidade do Estado de Santa Catarina (PPGAC/UDESC), ministrada pelas doutoras Maria Brígida de Miranda e Daiane Dordete, realizei um processo investigativo de atos ritualísticos, através do jogo nos procedimentos da Dramaturgia da Oralidade, onde avistei a figura de minha mãe, Edgleide Mulato, e de algumas de suas histórias orais, coletadas via Pesquisa de Escuta e documentava no Caderno de Memórias. Eis que minha ânima logo se revelou em cena e me apontou no horizonte três figuras elementares que estavam à espreita: a de uma moça que muito chorava por viver presa, a de um rapaz e a de um enorme pássaro. Essas três figuras foram sendo lapidadas nas salas de ensaio, até que dialogaram entre si e contaram um rito de passagem, tendo como protagonista a metáfora de um forte pássaro que vivia preso. Esse pássaro nada mais era do que a própria moça, projeção essa feita pela minha ânima acerca das narrativas de minha mãe.

Figura 1 - Dança Performática: Desalojada (2019) - Teatro do Centro de Artes da UDESC. Fotógrafa: Dayana Roberta Gomes.

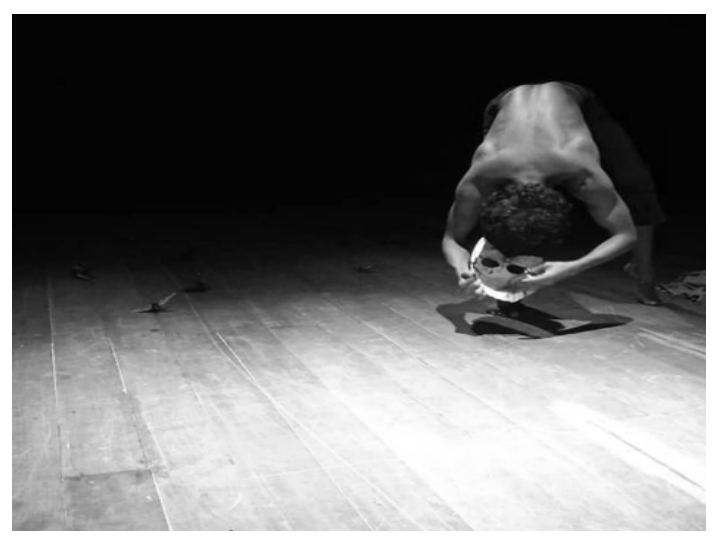

Fonte: Arquivo pessoal da artista-pesquisadora. 
Já com a cena performática estruturada, prestes a me apresentar, me vi diante não apenas da narrativa de vida de minha mãe - já que tive como mote criativo sua história -, mas de outras mulheres que muito choraram ao longo de suas vidas, por se verem presas aos padrões construídos pela sociedade patriarcal e terem sido impedidas de voar feito pássaros. Constatei também que inúmeras são as ânimas que se veem e se sentem presas aos porões das intimidades e obscuridades dos homens, sem poder ser vistas, valorizadas, contempladas. Minha ânima, pois, também esteve neste lugar de negação, por isso a urgência de reconhecer, reunir e falar sobre os atos misóginos. Esse grito/urro que partiu das entranhas d'alma não diz respeito apenas a uma pessoa especificamente, mas a milhares de indivíduos que muitas vezes desconhecemos.

Essa comunicação cênica foi intitulada $D e$ salojada (2019) e faz parte de um conjunto de cenas que está sendo estruturada em uma pesquisa de doutoramento, sob orientação da doutora e feminista Maria Brígida de Miranda, com coorientação da artista da cena e doutora Sandra Meyer.

\section{Conclusão - Estradas que galguei, aquilo que em mim permaneceu ou atravessou}

$O$ interesse em falar sobre minha feminilidade nas artes da cena surgiu quando me recordei das situações nefastas experienciadas por mim na infância, num momento em que convivi em um ambiente com sujeitos misóginos que afirmavam que eu externava muito meu lado feminino e que isso era altamente vergonhoso para eles. Ao falarem isso, me colocavam em um traçado de inferioridade, comparativamente a outras pessoas. As memórias advindas dessas experiências se tornaram gatilhos para a criação de atos performáticos.

Aliados às memórias e aos conhecimentos fomentados por Jung acerca da ânima, vim realizando estudos autobiográficos e me inteirando de minha consciência pessoal/coletiva. Compreender minha ânima, ou seja, minha feminilidade, me fará progredir nos processos de individuação e eman- cipar essas mulheres que habitam minhas camadas internas. Ao passo que vou realizando estudos acerca de minha feminilidade, vou desviando de padrões impostos a mim há décadas: queriam que eu fosse um sujeito viril, destemido e cortante, quer dizer, distante do meu eu-feminino. Sendo assim, fugir desses ideários culturalmente arraigados, por meio das artes da cena, de forma teórica e prática, significou afirmar que não estou de acordo com essas presilhas sociais, oriundas do sistema opressor.

Creio que tenham percebido que escrevi todo este artigo no feminino e que encontro neste meio de escrita uma das diversas maneiras de valorizar minha ânima, meu eu-feminino. Destaco que não se trata de pieguice, mas sim de correr o risco de abrir a escrita a tudo aquilo que sempre recebeu resistência da academia, devido ao medo das emoções, da sensibilidade, das subjetividades e mesmo das dúvidas (RAGO, 2013). É dessa maneira que viso contribuir para os rompimentos das barreiras impostas pela colonialidade social e acadêmica, me ligando a mim mesma, em um constante processo de individuação, desancorando aquelas que habitam meu lado interior.

Quanto ao processo prático acima apresentado, tendo como base noções ritualísticas para a cena, afirmo que se trata de um caminho para a criação, em fase de confabulação, e de um jogo lúdico, altamente significativo e que precisa ser exercitado, para então observar os processos metodológicos. As informações colhidas ao longo da Pesquisa de Escuta foram sendo documentadas no Caderno de Memórias, sendo este um diário de bordo que a pesquisadora carrega consigo mesma a fim de inserir informações relevantes, como frases, poemas, textos e objetos que serviram de estudo. Este caderno não pode ser compartilhado com outros indivíduos que não fizeram parte da jornada em campo, pois trata-se de informações confidenciais que interessam tão somente a quem se dedicou à pesquisa. Os conteúdos coletados servirão de base para a criação performática.

Para a criação do processo Desalojada (2019) - relatado acima-, fizuso de processos em Dança, pois 
[...] enxergo que dançar é abrir e/ou fechar sendas artísticas, onde se ampliam horizontes acerca do que por ora é expresso. Ou seja, dançar é algo transcendental. Ao longo desses estudos, reconheci que os corpos em estado de dança, ou não, podem ser vistos como lugares de ritos (expressões) e mitos (narrativas), que ultrapassam todas as noções hegemônicas que circundam o ato de dançar, fazendo com que repensemos novas criações e suas danças, os quais fazem eclodir perguntas como: são possíveis outras danças; e quais estão por vir? Partindo desse questionamento, desde 2013, venho me dedicando aos entendimentos do corpo através da linguagem da dança, tendo-a como plataforma para a criação cênica e o autoconhecimento. (NUNES, 2020a, p. 412).

Em cada empreitada cênica, invisto em minha ânima e descubro parte das coisas que desconhecia. Elas sempre me guiam no encontro comigo mesma, com minha essência feminina. Neste artigo, pode-se perceber que há uma confluência entre Teoria Analítica Junguiana, Corpo e Memória, os quais desaguam em comunicações cênicas e em encontro comigo mesma.

\section{Referências}

BUTLER, Judith. Problemas de Gênero: feminismo e subversão da identidade / 17. Ed. Judith Butler, Rio de Janeiro: Civilização Brasileira, 2019.

HALL, Calvin S. Introdução à psicologia junguiana / Calvin S. Hall, Vernon J. Nordby; produção de Heloysa de Lima Dantas. - [1. Ed. 11. Reimpressão] - São Paulo : Cultrix, 2014.

JUNG, Carl Gustav. Os arquétipos e o inconsciente coletivo. $2^{\circ}$ ed. Petrópolis: Vozes, 2000.

NUNES, João Vítor Ferreira. A força e a chuva feminina em um sertão bem masculino: imersão performática nos ritos de passagem de Bia Mulato pela metodologia em arte / João Vítor Ferreira Nunes, 245 f. Dissertação (Mestrado) - Universidade Federal do Rio Grande do Norte. Centro de Ciências
Humanas, Letras e Artes. Programa de Pós-graduação em Artes Cênicas, Natal/RN, 2019.

NUNES, João Vítor Ferreira. Escutar, Escrever e Encenar: Intersecções Entre Histórias Orais E Dança Performática. In: GUARATO, Rafael; MARQUES, Roberta; CADÚS, Eugênia (Org.) Memórias e Histórias da Dança Por Vir, p. 412-425. Salvador / ANDA, 2020a.

NUNES, João Vítor Ferreira. ÂNIMA E(M) PERFORMANCE: Cartografia poética da feminilidade. Artes da Cena (Art on Stage), v. 6, n. 1, p. 186-207, 2020b. DOI: https://doi.org/10.5216/ac.v6i1.63327. Acessado em: 17 set. 2020.

NUNES, João Vítor Ferreira; ARAUJO, Mariclécia Bezerra de; OLIVEIRA, Heráclito Cardoso de. Poéticas da Saudade e do Encantamento: Ritos Femininos como Norteadores de Processos na Seara das Artes Cênicas. p. 55 - 69. In: Ficções insurgentes: artes vivas em estados de emergência / Jussara Belchior Santos... [et al.]. 1. Ed. - Florianópolis/ SC: Caiapontes Edições, 2020c, 336 p. DOI: https:// doi.org/10.29327/532466.1-4. Acessado em: 27 dez. 2020.

RAGO. Margareth. A aventura de contar-se: feminismo, escrita de si e invenções da subjetividade. São Paulo: Editora Unicamp, 2013.

Recebido: 13/09/2021

Aceito: 15/10/2021

Aprovado para publicação: 23/11/2021

Este é um artigo de acesso aberto distribuído sob os termos de uma Licença Creative Commons Atribuição 4.0 Internacional. Disponível em: http://creativecommons.org/licenses/by/4.0.

This is an open-access article distributed un- 
der the terms of the Creative Commons Attribution License 4.0 International. Available at: http://creativecommons.org/licenses/by/4.0.

Ce texte en libre accès est placé sous licence Creative Commons Attribution 4.0 International. Disponible sur: http://creativecommons.org/licenses/by/4.0. 